\title{
Welfare Effects of Intellectual Property in a North-South Model of Endogenous Growth with Comparative Advantage
}

\author{
Gilles Saint-Paul \\ Toulouse School of Economics and Birkbeck College
}

\begin{abstract}
:
This paper develops a model for analyzing the costs and benefits of intellectual property enforcement in LDCs. The North is more productive than the South and is the only source of innovator. There are two types of goods, and each bloc has a comparative advantage in producing a specific type of good. If comparative advantage is strong enough, even under piracy there are goods that the South will not produce. Piracy will then lead to a reallocation of innovative activity in favor of these goods. That may harm consumers (including consumers in the South) to the extent that these goods have smaller dynamic learning externalities than the other goods, and that their share in consumption is small. Thus, whether or not piracy is in the interest of the South depends on how important are the goods for which it has a comparative advantage to its consumers, and what the growth potential of these goods is. While, all else equal, the North tends to lose more (or gain less) from piracy than the South, because monopoly profits eventually accrue to the North, the South may lose more than the North if there is a strong enough home bias in favor of the goods for which it has a comparative advantage.
\end{abstract}

JEL: F12, F13, O30, O34

Keywords: Piracy; intellectual property; innovation; growth; comparative advantage

Correspondence: gstpaul@univ-tlse1.fr 


\section{Introduction}

The extent to which developing countries should enforce intellectual property rights is a hotly debated topic. It is often heard that not doing so would allow a cheap access to important products such as drugs. Some authors also point out that in the nineteenth century, the US itself did not recognize foreign patents.

While the argument that a given small country can be made better-off by freeriding on intellectual property in the rest of the world is straightforward, empirically things are not so clear-cut: While Gould and Gruben (1996) find that lower enforcement of Intellectual property reduces growth in a cross-section of countries, a number of authors find adverse effects on foreign direct investment, exports and licensing by US high-tech firms (See Lee and Mansfield (1996), Smarczynska (2002), Smith, P. (1999), and Yang, G. and K. Maskus (1998)).

This paper develops a model for analyzing the costs and benefits of IP enforcement in LDCs. It is an endogenous growth model in the fashion of Grossman and Helpman (1991), with two countries, North and South. Innovation only takes place in the North. The North is more productive than the South. There are two types of goods, and each bloc has a comparative advantage in producing a specific type of good. If the South does not enforce IP (piracy), then it is able to manufacture goods invented in the North without paying royalties. These goods are sold at marginal cost instead of monopoly price, which benefits world consumers from a static viewpoint. If comparative advantage is strong enough, even under piracy there are goods that the South will not produce. Piracy will then lead to a reallocation of innovative activity in favor of these goods. That may harm consumers (including consumers in the South) to the extent that these goods have smaller dynamic learning externalities than the other goods, and that their share in consumption is small. Thus, whether or not piracy is in the interest of the South depends on how important are the goods for which it has a comparative advantage to its consumers, and what the growth potential of these goods is. While, all else equal, the North tends to lose more (or gain less) from piracy than the South, because monopoly profits eventually accrue to the North, the South may lose more than the North if there is a strong enough home bias in favor of the goods for which it has a comparative advantage.

We also provide some numerical results on how the monopoly markup affects the gains or losses from piracy to the North and the South. Casual intuition would suggest that piracy is more beneficial to welfare if markups are lower, since piracy eliminates the markup and brings prices down to marginal costs. However, this ignores the fact that the markup depends on the price-elasticity of demand, i.e. on how new goods are complementary with existing goods. When the elasticity falls, it means that complementarities are stronger, so that introducing new goods is more valued. This effect tends to magnify the welfare losses from having less innovation in one sector because of piracy. We show that under certain parameter values, a larger markup makes the South more likely to lose from its own piracy.

Our results are reminiscent of three related papers: Diwan and Rodrik (1991) consider the benefits of IPR in the South when there exists a range of products that it specifically consumes. Greater specificity of these products make it more costly for the South to opt for piracy, as it will get less innovation for the products that it needs. Their paper, however, is static and does not consider endogenous growth or comparative advantage. Thoenig and Verdier (2003) argue that the threat of piracy 
will induce the North to invest in more complex, skill-intensive technologies that are harder to imitate; the argument rests on a direct link between complexity and imitation, while the effects discussed here are relative price effects. ${ }^{1}$ Finally, the paper which is closest to the present one is Gancia and Bonfiglioli (2007). Their model carries a similar message, but using a Dornbusch-Fischer-Samuelson (1997) - type model. Furthermore, their model assumes that imitators in the South get monopoly rents, which changes the analysis of the trade-off between static and dynamic gains.

\section{The Model}

There are two countries, denoted by A and B, and two types of goods, denoted by 1 and 2. Within each type there potentially is a continuum of goods. Each good is produced with a linear technology which uses labor only. At each date $t$ there is a continuum of goods, with a mass $N_{i}$ of goods of type $i$. Goods of either type are indexed by $k \in\left[0, N_{i}\right]$. Goods of type 1 differ from goods of type 2 in that the relative productivity of country B is not the same. Specifically, country A produces all goods with a unit productivity. Country B produces goods of type 1 with productivity $b$ and goods of type 2 with productivity $a$. We assume that country B is less developed than country $\mathrm{A}$, and that it has a comparative advantage in producing 1-goods. That is,

$$
a<b<1
$$

Each country has a representative consumer. Times is continuous. The representative consumer in country $j$ maximizes

$$
V_{j}=\int_{0}^{+\infty} U_{j t} e^{-\rho t} d t
$$

where $U_{j t}$ is intratemporal utility at date $t$. Utility is allowed to differ between the two countries, embodying the possibility of home bias:

$$
\begin{aligned}
& U_{A}=\alpha \ln C_{1 t}^{A}+(1-\alpha) \ln C_{2 t}^{A}-(\alpha \ln \alpha+(1-\alpha) \ln (1-\alpha)), \\
& U_{B}=\beta \ln C_{1 t}^{B}+(1-\beta) \ln C_{2 t}^{B}-(\beta \ln \beta+(1-\beta) \ln (1-\beta)),
\end{aligned}
$$

where $C_{i t}^{j}, i \in\{1,2\}, j \in\{A, B\}$, is the aggregate consumption index of goods of type $i$ in country $j$, given by

$$
C_{i t}^{j}=\left(\int_{0}^{N_{i t}} c_{i j t}(k)^{\frac{\sigma-1}{\sigma}} d k\right)^{\frac{\sigma}{\sigma-1}}
$$

where $c_{i j t}(k)$ is consumer $j^{\prime} s$ consumption of the $i$-good indexed by $k$ at date $t$.We assume $\alpha \leq \beta$, so that there will be home bias if this inequality strictly holds. The demand function for good $k$ of type $i$ coming from country $j$ is

$$
c_{i j t}(k)=s_{i j} \frac{Y_{j t}}{\bar{p}_{i t}}\left(\frac{p_{i t}(k)}{\bar{p}_{i t}}\right)^{-\sigma},
$$

\footnotetext{
${ }^{1}$ Other related works include Goh and Olivier (2003) and Grossman and Lai (2001).
} 
where $Y_{j t}$ is aggregate nominal income in country $j$ at $t ; p_{i t}(k)$ is the price of the good considered; $s_{i j}$ the appropriate income share $\left(s_{1 A}=\alpha ; s_{2 A}=1-\alpha ; s_{1 B}=\right.$ $\left.\beta ; s_{2 B}=1-\beta\right)$; and $\bar{p}_{i t}$ the appropriate price index for $i$-goods:

$$
\bar{p}_{i t}=\left(\int_{0}^{N_{i t}} p_{i t}(k)^{1-\sigma} d k\right)^{\frac{1}{1-\sigma}} .
$$

Country $j$ is endowed with $L_{j}$ units of production labor. Furthermore, country $A$ is endowed with a stock $L_{R}$ of researchers, who produce new blueprints of either type. Thus, $\mathrm{R} \& \mathrm{D}$ can only take place in country $A$. The cost of producing a new good is the same irrespective of the type of the good. Once the good is invented, the inventor holds a monopoly right forever on the good. Researchers decide exante whether to try and invent a 1-good or a 2-good. Thus, they all specialize in the good that yields the largest present discounted value (PDV), unless the two PDVs are equal, in which case they are indifferent. While they have a fixed labor endowment, they have a small, infinitesimal disutility of labor, so that they would not work for a zero income. Therefore, if producing a new blueprint in both types of goods yields a zero or negative present discounted value, researchers do not work at all and no innovation takes place.

To guarantee sustained long-run growth, I assume, as the literature often does, that the cost of inventing new blueprints is proportional to the total number of goods of the same type $N_{i t}$. Thus, if $\theta_{t}$ is the proportion of researchers working on 1-goods, we have

$$
\begin{aligned}
& \dot{N}_{1 t}=\gamma_{1} \theta_{t} N_{1 t}, \\
& \dot{N}_{2 t}=\gamma_{2}\left(1-\theta_{t}\right) N_{2 t} .
\end{aligned}
$$

Note that the $\gamma$ s are allowed to differ between the two types of goods: one type of good may have stronger dynamic learning externalities than the other.

We will characterize equilibrium in two different cases: 1. Country B does not enforce any intellectual property by country A, and can export the products it copies to country A. In such a case any good $i$ can be produced by the patent holder in country $A$ plus a fringe of perfect competitors in country B. 2. Country B fully enforces intellectual property rights. In such a case only the patent holder can produce a good. Patent holders can be located in either country ${ }^{2}$, but all monopoly profits accrue to country A.

We now describe the main properties of the solution under different policy regimes, relegating proofs to the Appendix. We first characterize the allocation of resources and prices at a given date, and then study the determinants of innovation and the evolution of the number of goods. We shall express prices in terms of labor in country A. Its wage $w_{A}$ is therefore normalized to $w_{A}=1$. We will also denote by $\mu=\frac{\sigma}{\sigma-1}$ the monopoly markup.

\section{The Intra-Period Equilibrium}

This section discusses how the intra-period equilibrium is determined. It describes its main economic properties and spells out the solution for all the endogenous

\footnotetext{
${ }^{2}$ Or, equivalently, extract all the rents by licensing to a monopoly based in country B.
} 
variables in all the specific regimes. The precise equilibrium conditions, that are standard, and associated mathematical derivations are left to the appendix.

\subsection{Full Piracy}

Let us first analyze equilibrium in the case of full piracy. That means that any firm in country B can produce and export any existing good. However, only the patent holder can produce a good in country A.

Depending on the model's parameters - in particular the countries' relative sizes, their relative productivity level, and the level of the monopoly markup - the economy can be in one of four different regimes. The properties of these regimes are summarized in Table 1 and graphically represented in Figure 1. For each country $j=A, B$ and each good type $i=1,2$, we denote the nominal wage levels by $w_{j}$, the world price by $p_{i}$, employment in country $j$ and good type $i$ by $L_{i j}$, GNP-which is equal to GDP under piracy but not under enforcement-by $Y_{j}$, and the profits of the patent holder should it decide to produce a $j$-good in country A by $\pi_{j}$.

If country A is large enough (Regimes P1, P2, and P3), country B will only produce good 1 . In such a case, producers of 2-goods in country A have strictly positive profits: rather than copying 2-goods, country B focuses on 1-goods in which it has a comparative advantage. Consequently, there is an incentive to innovate in these goods. In regime P1, country A only produces 2-goods; a producer of 1-goods would make strictly negative profits. The condition for this regime to prevail is denoted by (CP1). In regime P2, it produces both types of goods, and charges a monopoly price on the 2 -goods, while it makes zero profits in the 1 -goods. The same occurs in regime P3 except that, in that regime, producers of 2-goods charge a limit price equal to the productivity gap between the two countries. In contrast, if country $\mathrm{A}$ is not large enough relative to country $\mathrm{B}$, the latter produces both types of goods, and it is impossible for firms in country A to charge more than their cost. Thus profits are zero even for 2 -goods producers, and there is no incentive for innovation.

Table 1 - Equilibrium Characterization under Full Piracy

\begin{tabular}{|c|c|c|c|c|}
\hline Regime & P1 & $\mathrm{P} 2$ & P3 & $\mathrm{P} 4$ \\
\hline $\begin{array}{l}\text { Condition on } \\
z=\frac{\alpha \mu L_{A}}{(1-\beta) L_{B}}\end{array}$ & $\begin{array}{l}a \mu<z<b \\
(\mathrm{CP} 1)\end{array}$ & $a \mu<b<z$ & $b<a \mu<z$ & $z<a \mu$ \\
\hline$w_{A}$ & 1 & 1 & 1 & 1 \\
\hline$w_{B}$ & $z$ & $b$ & $b$ & $a$ \\
\hline$p_{1}$ & $z / b$ & 1 & 1 & $a / b$ \\
\hline$p_{2}$ & $\mu$ & $\mu$ & $b / a$ & 1 \\
\hline$L_{2 A}$ & $L_{A}$ & $\frac{(1-\alpha) L_{A}+b(1-\beta) L_{B}}{\alpha \mu+1-\alpha}$ & $\frac{(1-\alpha) L_{A}+b(1-\beta) L_{B}}{\alpha b / a+1-\alpha}$ & $L_{A}$ \\
\hline$L_{1 B}$ & $L_{B}$ & $L_{B}$ & $L_{B}$ & $\frac{\alpha L_{A}+a \beta L_{B}}{a}$ \\
\hline$Y_{A}$ & $\mu L_{A}$ & $(\mu-1) L_{2 A}+L_{A}$ & $(b / a-1) L_{2 A}+L_{A}$ & $L_{A}{ }^{a}$ \\
\hline$Y_{B}$ & $z L_{B}$ & $b L_{B}$ & $b L_{B}$ & $a L_{B}$ \\
\hline$\pi_{2}$ & $>0$ & $>0$ & $>0$ & $=0$ \\
\hline$\pi_{1}$ & $<0$ & $=0$ & $=0$ & $<0$ \\
\hline
\end{tabular}


Figure 1 - Specialization and Pricing Regimes, Piracy

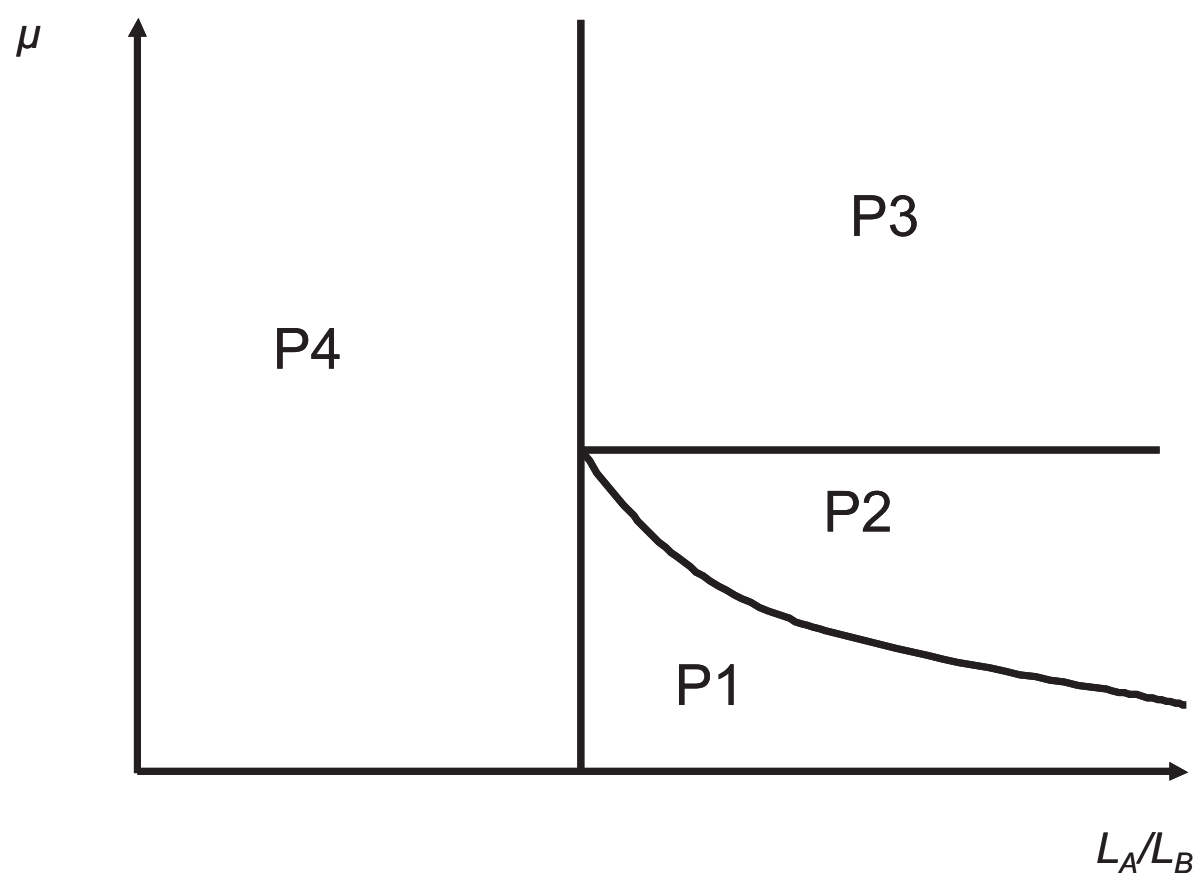

\subsection{Full Enforcement}

We now turn to the second case, where intellectual property is fully enforced worldwide. There are three possible regimes, that are summarized in Table 2 below. Again, depending on the relative size of country A, we have different specialization regimes. In all of them, patent-holders get positive profits, since property rights are enforced. From a static point of view, it is clear that enforcement redistributes income from country $\mathrm{B}$ to country $\mathrm{A}$, in the form of monopoly profits for patent holders in country A. Figure 2 illustrates the zone where each regime prevails. In regime E1, country A only produces 2 -goods and country B only produces 1 -goods. The associated condition is denoted by (CE1). In regime E2, country A produces both goods, and country B only produces 1-goods. Finally, in regime E4, country B produces both goods and country A only produces 2-goods. Note that the zones where these patterns of production prevail are substantially different from the enforcement regime. Also, profits can be written $\pi_{i}=q_{i} / N_{i}$, where $q_{i}$ is a constant which only depends on the regime being considered. 
Table 2 - Equilibrium Characterization under Full Enforcement

\begin{tabular}{llll}
\hline \hline Regime & E1 & E2 & E4 \\
\hline Condition on & $a<z^{\prime}<b$ & $z^{\prime}>b$ & $z^{\prime}<a$ \\
$z^{\prime}=\frac{\alpha \mu L_{A}}{[(1-\beta)+(1-\alpha)(\mu-1)] L_{B}}$ & $(\mathrm{CE} 1)$ & & \\
\hline$w_{A}$ & 1 & 1 & 1 \\
$w_{B}$ & $z^{\prime}$ & $b$ & $\mu a / b$ \\
$p_{1}$ & $\mu z^{\prime} / b$ & $\mu$ & $\mu$ \\
$p_{2}$ & $\mu$ & $\mu$ & $L_{2}$ \\
$L_{2 A}$ & $L_{A}$ & $z^{\prime} L_{B}$ & $\frac{(\alpha \mu+1-\alpha) a L_{B}-(1-\beta) a L_{B}+\alpha \mu L_{A}}{\mu a}$ \\
$L_{1 B}$ & $L_{B}$ & $L_{B}$ & $\mu L_{A}+(\mu-1) a L_{B}$ \\
$Y_{A}$ & $\mu L_{A}+(\mu-1) L_{B} z^{\prime}$ & $\mu L_{A}+(\mu-1) b L_{B}$ & $a L_{B}$ \\
$Y_{B}$ & $z^{\prime} L_{B}$ & $b L_{B}$ & $(\mu-1) \frac{L_{A}+a\left(L_{B}-L_{1 B}\right)}{N_{2}}$ \\
$\pi_{2}$ & $(\mu-1) \frac{L_{A}}{N_{2}}$ & $(\mu-1) \frac{L_{2 A}}{N_{2}}$ & $(\mu-1) a \frac{L_{1 B}}{N_{1}}$ \\
$\pi_{1}$ & $(\mu-1) \frac{L_{B}}{N_{1}} z^{\prime}$ & $(\mu-1) \frac{b L_{B}+L_{A}-L_{2 A}}{N_{1}}$ & $(\mu)$ \\
\hline \hline
\end{tabular}

Figure 2 - Specialization and Pricing Regimes, Enforcement

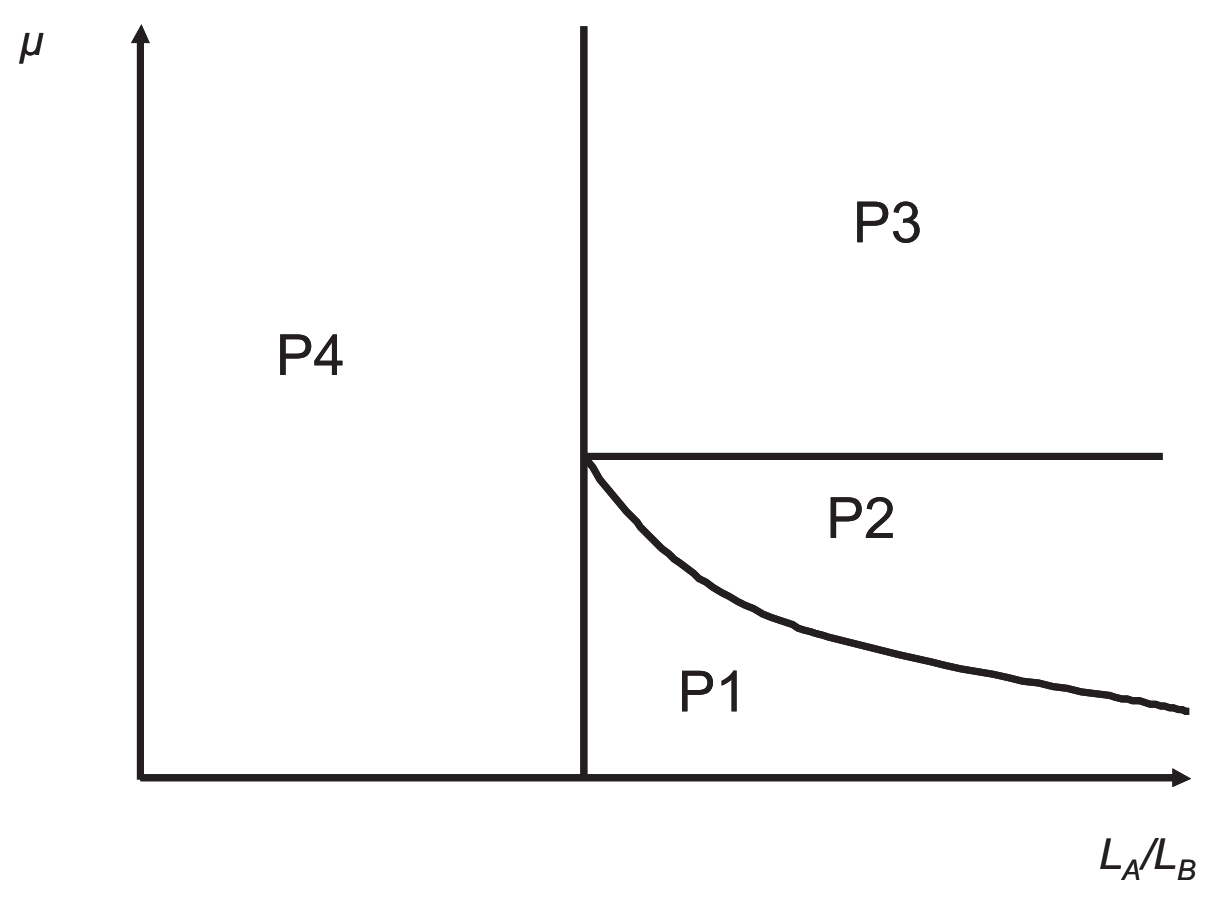

\section{Innovation}

To complete the model's characterization, we need to describe how the number of varieties in each type of good evolves. We do so by introducing innovation using the standard tools developed by the literature.

The $\mathrm{R}$ and $\mathrm{D}$ sector is competitive. All agents can borrow and lend at a fixed nominal rate $r$. If $V_{i}$ denotes the value of a patent associated with an $i$-good, then

$$
r V_{i}=\pi_{i}+\dot{V}_{i}
$$

In equilibrium, researchers allocate themselves between the two types of innovation. The labor market for researchers is perfectly competitive, so that they earn the same wage in each sector. 
Let us first consider the full enforcement case. If $\theta$ is interior, and we confine the analysis to this case, the expected value from one unit of research must be the same in both sectors, implying

$$
\gamma_{1} N_{1} V_{1}=\gamma_{2} N_{2} V_{2}
$$

Substituting (1) into (2), integrating forward and using (3), we get the equilibrium value of $\theta$ :

$$
\theta=\frac{\left(r \gamma_{1}+\gamma_{1} \gamma_{2}\right) q_{1}-r \gamma_{2} q_{2}}{\gamma_{1} \gamma_{2}\left(q_{1}+q_{2}\right)}
$$

Note that $\theta$ does not depend on $N_{1}$ and $N_{2}$, and is constant through time. It is increasing in the productivity of research for 1-goods $\gamma_{1}$ and the profitability of these goods $q_{1}$, and decreasing in $\gamma_{2}$ and $q_{2}$. Finally for $\theta$ to be interior, we need that

$$
\frac{r \gamma_{1} q_{1}}{r \gamma_{2}+\gamma_{1} \gamma_{2}} \leq q_{2} \leq \frac{\left(r \gamma_{1}+\gamma_{1} \gamma_{2}\right) q_{1}}{r \gamma_{2}}
$$

We can then compute the growth rate of the mass of goods for each variety

$$
\begin{aligned}
& \frac{\dot{N}_{1}}{N_{1}}=\frac{\left(r \gamma_{1}+\gamma_{1} \gamma_{2}\right) q_{1}-r \gamma_{2} q_{2}}{\gamma_{2}\left(q_{1}+q_{2}\right)}=g_{1} . \\
& \frac{\dot{N}_{2}}{N_{2}}=\frac{\left(r \gamma_{2}+\gamma_{1} \gamma_{2}\right) q_{2}-r \gamma_{1} q_{1}}{\gamma_{1}\left(q_{1}+q_{2}\right)}=g_{2} .
\end{aligned}
$$

In the no enforcement case, $\pi_{1} \leq 0$ always. If $\pi_{2}>0$, then $\theta=0$ and $g_{2}=\gamma_{2}$, while $g_{1}=0$. If $\pi_{2}=0$, then researchers are 'unemployed' and $g_{1}=g_{2}=\pi_{1}=\pi_{2}=0$.

\section{Welfare}

The regimes characterized in Tables 1 and 2 are valid at a point in time, but note that the conditions do not depend on the values of $N_{1}$ and $N_{2}$ (That is because preferences are Cobb-Douglas between the two aggregates). Therefore, if the economy is in a given regime at $t=0$, it will stay in that regime. If from time $t=0 \mathrm{on}, N_{1}$ and $N_{2}$ grow at constant rates $g_{1}$ and $g_{2}$, it is then easy to express the welfare of both countries as a function of their nominal national income, the price levels, the initial number of goods and their growth rates. We get

$$
U_{A t}=\frac{\alpha}{\sigma-1} \ln N_{1 t}+\frac{1-\alpha}{\sigma-1} \ln N_{2 t}+\ln Y_{A}-\alpha \ln p_{1}-(1-\alpha) \ln p_{2}
$$

where time indices have been dropped from $p_{i}$ and $Y_{A}$, because they are constant throughout if one remains in the same regime. Similarly,

$$
U_{B t}=\frac{\beta}{\sigma-1} \ln N_{1 t}+\frac{1-\beta}{\sigma-1} \ln N_{2 t}+\ln Y_{B}-\beta \ln p_{1}-(1-\beta) \ln p_{2} .
$$


The present discounted values are given by

$$
\begin{aligned}
V_{A}= & \int_{0}^{+\infty} U_{A t} e^{-\rho t} d t \\
= & \frac{\alpha}{\sigma-1}\left(\frac{\ln N_{10}}{\rho}+\frac{g_{1}}{\rho^{2}}\right)+\frac{1-\alpha}{\sigma-1}\left(\frac{\ln N_{20}}{\rho}+\frac{g_{2}}{\rho^{2}}\right) \\
& +\frac{\ln Y_{A}-\alpha \ln p_{1}-(1-\alpha) \ln p_{2}}{\rho} . \\
V_{B}= & \frac{\beta}{\sigma-1}\left(\frac{\ln N_{10}}{\rho}+\frac{g_{1}}{\rho^{2}}\right)+\frac{1-\beta}{\sigma-1}\left(\frac{\ln N_{20}}{\rho}+\frac{g_{2}}{\rho^{2}}\right) \\
& +\frac{\ln Y_{A}-\beta \ln p_{1}-(1-\beta) \ln p_{2}}{\rho} .
\end{aligned}
$$

To facilitate comparison, I will assume that the world economy is initially in a balanced growth path with enforcement, and compare each country's welfare if enforcement continues with its value if country B stops enforcing IPRs. If so, then under both alternatives $N_{i}$ grows at a constant rate and the above formulas may be applied. We assume full specialization of each country in the enforcement case, i.e. that (CE1) holds; and that $\frac{\alpha L_{A}}{(1-\beta) L_{B}}<\frac{b}{\mu}$, which, given (CE1), implies that (CP1) also holds. ${ }^{3}$ Therefore, we focus the discussion on the case where the economy is in regime P1 (resp. E1) under piracy (resp. enforcement). We thus have from Table 2 :

$$
q_{1}=(\mu-1) \frac{\alpha \mu L_{A} L_{B}}{(1-\beta) L_{B}+(1-\alpha)(\mu-1) L_{B}},
$$

and

$$
q_{2}=(\mu-1) L_{A}
$$

The following Table then summarizes the shifts in the variables of interest if the economy moves from an enforcement steady state to a no enforcement situation.

Table 3 - Changes in Relevant Variables When Piracy Is Introduced

\begin{tabular}{ll}
\hline \hline$\Delta \ln w_{B}$ & $\ln \left(1+\frac{(1-\alpha)(\mu-1)}{1-\beta}\right)$ \\
$\Delta \ln w_{A}$ & 0 \\
$\Delta \ln p_{2}$ & 0 \\
$\Delta \ln p_{1}$ & $-\ln \mu+\ln \left(1+\frac{(1-\alpha)(\mu-1)}{1-\beta}\right)$ \\
$\Delta g_{1}$ & $-\frac{\left(r \gamma_{1}+\gamma_{1} \gamma_{2}\right) q_{1}-r \gamma_{2} q_{2}}{\gamma_{2}\left(q_{1}+q_{2}\right)}<0$ \\
$\Delta g_{2}$ & $\frac{\left(r \gamma_{1}+\gamma_{1} \gamma_{2}\right) q_{1}-r \gamma_{2} q_{2}}{\gamma_{1}\left(q_{1}+q_{2}\right)}>0$ \\
$\Delta \ln Y_{B}$ & $\ln \left(1+\frac{(1-\alpha)(\mu-1)}{1-\beta}\right)$ \\
$\Delta \ln Y_{A}$ & $\ln \left(1-\alpha \frac{\mu-1}{\mu-\beta}\right)$ \\
\hline \hline
\end{tabular}

\footnotetext{
${ }^{3}$ The inequality $\frac{\alpha L_{A}}{(1-\beta) L_{B}}<\frac{b}{\mu}$ is equivalent to $z<b$, i.e. the second part of (CP1). To check the first part of (CP1), note that if (CE1) holds we have $z=\frac{\alpha \mu L_{A}}{(1-\beta) L_{B}}>\frac{a[1-\beta+(1-\alpha)(\mu-1)]}{1-\beta}$ $=a\left(\mu+(\mu-1) \frac{\beta-\alpha}{1-\beta}\right) \geq a \mu$, where the last inequality comes from the fact that $\alpha \leq \beta$.
} 
The day enforcement stops, producers of 1-goods in country B stop paying royalties to patent owners in country A. The price of 1-goods is driven to marginal cost in country B. Since country B has a comparative advantage in those goods, producers of 1-goods in country A would make losses. Consequently, innovation in that sector stops instantaneously in country A. All research effort is reallocated to 2-goods: Because country A has a comparative advantage in those goods, monopoly profits are maintained there in that sector despite that country B producers can freely copy the good and sell it at (country B's) marginal cost in world markets. Consequently, the world economy jumps to a new steady state where only 2-goods are invented. The growth rate of $N_{2}$ goes up while that of $N_{1}$ falls to zero.

When prices are expressed in units of labor in country A, we see that GNP falls in country A while it goes up in country B. Country A's patent holders lose profit income from country $\mathrm{B},{ }^{4}$ while at the same time the elimination of markups from country B's products drives its wage up.

The relative price of 1-goods may either go up or down: while the elimination of the markup pushes it down, the higher wage in country 1 pushes it up. If $\alpha=\beta$, then $p_{1}$ is unchanged. If $\alpha<\beta$ (home bias), $p_{1}$ rises. That is because the fall in the demand for 1-goods from consumers of country A (whose GNP falls) has a smaller effect than the rise in demand from consumers of country B (whose GNP goes up).

Intratemporal utility of consumers in country $\mathrm{B}$ goes up, given that the change in $p_{1}$ never exceeds the change in $w_{B}$. As for consumers in country A, their intratemporal utility may either go up or down, depending on whether or not the fall in $p_{1}$ is strong enough to outweigh the foregone profits from 1-goods.

What about intertemporal welfare? Using Table 3 and noting that $\mu=\sigma /(\sigma-1)$, we get that

$$
\begin{aligned}
\Delta V_{A}= & \frac{\mu-1}{\rho^{2}} \frac{\left(r \gamma_{1}+\gamma_{1} \gamma_{2}\right) q_{1}-r \gamma_{2} q_{2}}{\gamma_{1} \gamma_{2}\left(q_{1}+q_{2}\right)}\left(\gamma_{2}-\alpha\left(\gamma_{1}+\gamma_{2}\right)\right) \\
& +\frac{1}{\rho}\left[\ln \left(1-\alpha \frac{\mu-1}{\mu-\beta}\right)-\alpha \ln \left(1+\frac{(1-\alpha)(\mu-1)}{1-\beta}\right)+\alpha \ln \mu\right] \\
\Delta V_{B}= & \frac{\mu-1}{\rho^{2}} \frac{\left(r \gamma_{1}+\gamma_{1} \gamma_{2}\right) q_{1}-r \gamma_{2} q_{2}}{\gamma_{1} \gamma_{2}\left(q_{1}+q_{2}\right)}\left(\gamma_{2}-\beta\left(\gamma_{1}+\gamma_{2}\right)\right) \\
& +\frac{1}{\rho}\left[(1-\beta) \ln \left(1+\frac{(1-\alpha)(\mu-1)}{1-\beta}\right)+\beta \ln \mu .\right]
\end{aligned}
$$

To proceed, note that intertemporal optimization by consumers implies that ${ }^{5}$

$$
r=\rho .
$$

\footnotetext{
${ }^{4}$ These are the direct redistributive effects discussed, for example, by MacCalman (2000).

${ }^{5}$ To see that, note that with logarithmic preferences maximizing intertemporal utility is equivalent to maximizing $\int \ln Y_{t} e^{-\rho t} d t$, where $Y_{t}$ is expenditure at $t$. While the nominal interest rate $r$ is equal to $\rho$, the intertemporal marginal rate of substitution in consumption is greater than $\rho$, because the aggregate price level for composite good $i$ falls with time, reflecting innovation and greater product diversity.
} 
We can rewrite the preceding equations as

$$
\begin{aligned}
\Delta V_{A}= & \frac{\mu-1}{\rho^{2}} \frac{\left(\rho \gamma_{1}+\gamma_{1} \gamma_{2}\right) q_{1}-\rho \gamma_{2} q_{2}}{\gamma_{1} \gamma_{2}\left(q_{1}+q_{2}\right)}\left(\gamma_{2}-\alpha\left(\gamma_{1}+\gamma_{2}\right)\right) \\
& +\frac{1}{\rho}\left[\ln \left(1-\alpha \frac{\mu-1}{\mu-\beta}\right)-\alpha \ln \left(1+\frac{(1-\alpha)(\mu-1)}{1-\beta}\right)+\alpha \ln \mu\right] . \\
\Delta V_{B}= & \frac{\mu-1}{\rho^{2}} \frac{\left(\rho \gamma_{1}+\gamma_{1} \gamma_{2}\right) q_{1}-\rho \gamma_{2} q_{2}}{\gamma_{1} \gamma_{2}\left(q_{1}+q_{2}\right)}\left(\gamma_{2}-\beta\left(\gamma_{1}+\gamma_{2}\right)\right) \\
& +\frac{1}{\rho}\left[(1-\beta) \ln \left(1+\frac{(1-\alpha)(\mu-1)}{1-\beta}\right)+\beta \ln \mu .\right]
\end{aligned}
$$

The first terms of (5) and (6) represent the contribution to welfare of the dynamic effects of piracy on the evolution of $N_{i}$ : innovation now only takes place in 2-goods. Given condition (4), this contribution is negative in country A if and only if

$$
\frac{\gamma_{2}}{\gamma_{1}+\gamma_{2}}<\alpha
$$

For country B, a similar condition holds for dynamic gains to be negative:

$$
\frac{\gamma_{2}}{\gamma_{1}+\gamma_{2}}<\beta
$$

Hence, the dynamic effects of piracy are more likely to be negative, (i) the greater the shares of 1 -goods in consumption $\alpha$ and $\beta$, and (ii) the greater the level of the dynamic externality in 1 -goods, $\gamma_{1}$, relative to 2 -goods, $\gamma_{2}$. The intuition is straightforward: The welfare loss from piracy is greater if 1-goods have a greater potential to grow, and if they are more important to consumers.

The second terms of (5) and (6) are the static gains from piracy. For country $\mathrm{B}$, they are always positive, since they result entirely from lower markups. Consequently, if (8) is violated, country B unambiguously gains from piracy. What if (8) holds? Static gains are positive, while dynamic gains are negative. One can check that the RHS of (6) is positive and then negative as $\rho$ falls. Thus there exists a critical level of the rate of time preference below which piracy harms country $\mathrm{B}$, and above which it benefits country B.

Turning now to country A, note that since $\beta \geq \alpha$ ("home bias"), $1+\frac{(1-\alpha)(\mu-1)}{1-\beta} \geq$ $\mu$, implying that the static gains for country A are negative ${ }^{6}$ : it loses more from foregone royalties than from a fall in the price of 1-goods, which it cares less about than 2-goods. Therefore, country A will always oppose piracy if (7) holds. If (7) does not hold, country A will oppose piracy if the discount rate is high but support it if the discount rate is low, as piracy then reshuffles research into the goods with more favorable learning externalities given its preferences.

\footnotetext{
${ }^{6}$ If $\beta<\alpha$, the third term in the static gains for country A dominates the second, implying that it would gain from piracy if $\mu$ is very large. However, for $\mu$ close enough to one, the static gains are again negative, since a first-order Taylor approximmation yields $\frac{\alpha-\beta}{1-\beta}-\frac{1}{1-\beta}<0$.
} 
To summarize, the preceding discussion suggests that the long-run gains from IP enforcement to each country depend on how the expenditure share of 1-goods compare to the relative growth potential of 2 -goods. For an equal growth potential, long-run gains from IP enforcement are positive if the expenditure share on 1-good exceeds $50 \%$ (or, more generally, the expenditure share on 2-goods).

If $\alpha=\beta$, then country $\mathrm{A}$ is always less likely to gain/more likely to lose from piracy. However, the assumption $\beta>\alpha$, i.e. that goods in which a country has a comparative advantage are also goods that its consumers like better relative to other consumers in the rest of the world ("home bias"), is also intuitive. Such a property could arise if economies were once closed and if productivity levels were determined by learning by doing, or tastes by habit formation.

If 1-goods are more important to consumers in country B than to consumers in country A, and if at the same time it has a comparative advantage in producing these goods, then it may actually lose more from piracy than country A: While static gains are negative for country A and positive for country B, condition (8) is more likely to hold than (7), so that country B is more likely to suffer dynamic losses from piracy; that is because it cares more about the goods for which innovation has fallen.

Finally, one can just check that computing dynamic gains amount to computing the change in growth rates for the aggregate consumption index. The growth rate of the aggregate consumption index is

$$
g_{A}=\frac{\alpha g_{1}+(1-\alpha) g_{2}}{\sigma-1}
$$

in country $\mathrm{A}$ and

$$
g_{B}=\frac{\beta g_{1}+(1-\beta) g_{2}}{\sigma-1}
$$

in country B. Using the above formulae, we see that piracy reduces growth in country $\mathrm{A}$ if and only if

$$
\alpha>\frac{\gamma_{2}}{\gamma_{1}+\gamma_{2}}
$$

which is a sufficient condition for country A to always lose in welfare terms. Similarly, country B's growth is reduced if and only if:

$$
\beta>\frac{\gamma_{2}}{\gamma_{1}+\gamma_{2}}
$$

which is a necessary condition for welfare to fall in country B. Finally note that if $\beta>\alpha$, country $\mathrm{B}$ grows less fast than country $\mathrm{A}$ in the piracy regime. However, that is in terms of the relevant basket of goods consumed by its residents. Both countries would grow at the same rate in terms of a common basket of goods.

\section{The Role of the Markup}

In this section, I provide further numerical results with respect to the effect of the markup $\mu$. This parameter plays a twin role: as it goes up, so does the static loss 
from monopoly pricing. But, at the same time, complementarity between goods goes up, and people value innovation more. This can be seen in (5) and (6), where the dynamic component is proportional to $\mu-1$. Therefore, all gains and losses from piracy are commensurate with $\mu-1$ : the markup gives us the order of magnitude of both the level of monopoly distortions and the hedonic value of greater product diversity. ${ }^{7}$

I report the results of numerical simulations where country B may lose from IP enforcement. In the first simulation, (Figures 3-5, see Appendix B), the parameters are $L_{A}=L_{B}=1, \alpha=\beta=0.3, a=0.2, b=0.9, \gamma_{1}=0.02, \gamma_{2}=0.006, \rho=$ 0.03. Here dynamic losses come from the fact that 2 -goods involve smaller learning externalities $\left(\gamma_{2}<\gamma_{1}\right){ }^{8} \quad$ Figure 3 plots the evolution of the static and dynamic gains for country A. Both are negative: country A loses both from slower growth and foregone profits. Furthermore, losses go up with the markup. As for country B (Figure 4), it has static gains from the elimination of monopoly pricing, and dynamic losses from lower innovation in 1-goods. Both gains and losses are increasing with the markup. Whether the country gains or loses on net depends on the discount factor. Figure 5 plots the value of $\rho$ below which piracy does not pay for country B. A striking property is that it is increasing with the markup; that suggests that as goods become more complementary, the value of having more 1-goods becomes stronger relative to the greater static losses from monopoly pricing. Equivalently, given $\rho$, a greater markup makes it more likely that piracy is not in the interest of country B. Note however that with these parameter values the critical $\rho$ is very small.

In the second simulation, (Figures 6-9, see Appendix B), parameters are $L_{A}=$ $L_{B}=1, \alpha=0.2, \beta=0.6, a=0.2, b=0.9, \gamma_{1}=\gamma_{2}=0.02, \rho=0.01 .^{9}$ Dynamic losses to country $\mathrm{B}$ now come from the fact that it puts a high weight on 1-goods, contrary to country A. As Figure 6 shows, country A has static losses from piracy, but positive dynamic gains as innovation is reallocated to the goods on which it spends a high share. Thus it will prefer piracy if patient enough. Figure 7 plots the critical discount rate of country A beyond which it prefers piracy. It is again increasing with the markup, meaning that the higher the monopoly rent, the more likely it is that the innovative country A prefers piracy! This paradoxical result comes from the fact that the structure of innovation is inefficient from country A's perspective, because too much effort is devoted to producing the 1-goods that its consumers value little. Given that country B is not productive enough to compete with country A in the production of 2-goods, letting it engage in piracy triggers a reallocation of research in favor of 2-goods which is quite welcome by consumers in country A, provided they are patient enough to be willing to trade foregone royalties against future increments in the number of varieties it likes. Greater complementarities between goods increases the foregone monopoly rents as well as the utility gain from having more 2-goods in the future, and the simulations tells us that the latter effect dominates. Turning now to country B, net gains are reported on Figure 8. The pattern is similar to the preceding simulation. Again, greater monopoly power

\footnotetext{
${ }^{7}$ While it is possible to disentangle the two effects by adding some power of $N$ to the utility function (Bénassy, 1996), the view that the elasticity of demand is lower when new goods are more valuable is intuitively appealing.

${ }^{8}$ One may check that for these parameters, the economy is in regimes P1 and E1 for the values of $\mu$ that are used.

${ }^{9}$ The value of $\rho$ was lowered so as to prevent $\theta$ from being negative.
} 
makes it more likely that country B loses from piracy, as the critical discount rate is again increasing with $\mu$. Here again, the critical discount rates are quite low: static effects seem to dominate for plausible values of the discount rate.

\section{Summary and Conclusion}

This paper has developed a particular model of directed technical change in order to study the effect on innovation and welfare of the enforcement regime for intellectual property in less developed countries. The model yields a number of insights with respect to the costs and benefits of piracy in an international trade context. First, piracy triggers a reallocation of $\mathrm{R}$ and $\mathrm{D}$ in favor of the goods (2-goods) in which the richer country has a comparative advantage. Second, this reallocation tends to reduce welfare if (i) dynamic learning externalities are high in 1-goods relative to 2 -goods, and if (ii) the share of 1-goods in consumption is high. Third, if consumers across the world spend the same fraction of their income on each type of goods, the richer country is more likely to incur a net loss than the poorer, because of the foregone royalties associated with its intellectual property. However, if there is a "home bias" in that consumers spend more on the goods in which their country has a comparative advantage than foreign consumers, then the poorer country may lose, and it will grow less fast, in utility terms, under the piracy regime than the richer country. Finally, a higher monopoly power does not increase the net social gains from piracy, because it is associated with greater complementarities between goods which also makes innovation more valuable.

We have seen that for dynamic losses to arise from piracy, the consumption share of the goods where the South have a comparative advantage must be relatively large, and the learning externalities in those goods must be relatively strong. Arguably, this is not very plausible empirically if one considers that the goods produced by the South are more mature and have a lower potential for innovation; on the other hand, even in this case the South may lose if its home bias is strong enough; furthermore, dynamic losses would presumably be more likely if the total stock of researchers in the North were not fixed as in the model, but endogenous instead.

This model has only considered one channel through which piracy may harm the country which engages in it: the diversion of innovation in favor of goods in which it does not have a comparative advantage. Other channels exist, such as reductions in exports, licensing and foreign direct investment: see for example Smarczynska, B. (2002), or other references in Saint-Paul (2005). Formalizing these aspects is likely to be a productive direction for further research, that would include a distinction between different channels of piracy; presumably, licensing is vulnerable to piracy because of cheating, say underreporting of sales of the licensed goods, or secret resale of the technology to an other firm, while FDI is vulnerable to direct copying of the technology. On the other hand, exports can lead to piracy only through reverse engineering; these differences may explain how lower enforcement of intellectual property affects these alternative trade channels. 


\section{Appendix A: Derivation of Analytical Results}

\section{Derivation of the Four Piracy Regimes}

\section{Country B Only Produces 1-Goods}

Let us first characterize an equilibrium where country B only produces 1-goods. We will normalize the wage of workers in country A to $w_{A}=1$. Country B can produce any good competitively. Therefore, its producers will pin down the price of 1-goods:

$$
p_{1}(k)=w_{B} / b=p_{1}, \forall k .
$$

2 -goods can be produced in country B at cost $w_{B} / a$. Therefore,

$$
p_{2}(k)=p_{2}=\min \left(\frac{w_{B}}{a}, \mu w_{A}\right),
$$

where $\mu=\sigma /(\sigma-1)$ is the monopoly markup one would observe absent competition from country B.

In equilibrium, it must be better to buy goods from competitive producers in country $\mathrm{B}$ than from the patent holder in country A. Therefore, one must have

$$
w_{B} / b<\mu w_{A}=\mu .
$$

To compute equilibrium quantities, note that national income in country B is

$$
Y_{B}=w_{B} L_{B}
$$

Country A potentially produces both types of goods. Let $L_{i A}$ be the labor input in country A devoted to $i$-goods. Then:

$$
Y_{A}=p_{2} L_{2 A}+\frac{w_{B}}{b} L_{1 A}
$$

That equation is the GDP at market prices national income identity, saying that GDP is the total value of final goods being sold.

Equilibrium of supply and demand for either type of good leads to the following equality, which must hold in equilibrium:

$$
\alpha p_{2} L_{2 A}=w_{B}\left[\frac{1-\alpha}{b} L_{1 A}+(1-\beta) L_{B}\right]
$$

\section{P1: Monopoly Pricing, Country A Only Produces 1-Goods}

Let us first look for an equilibrium with monopoly pricing for the 2-goods, and no production of good 1 in country $\mathrm{A}$. Then $w_{B}$ must be such that

$$
\mu<w_{B} / a,
$$

and

$$
w_{B} / b<w_{A}=1 .
$$

The first condition states that the monopoly price of 2-goods is lower than their production cost in country B. The second condition says that the cost of 1-goods in country A is higher than in country B, so that no holder of a patent for a 1-good in country A wants to actually produce. 
We then have $L_{1 A}=0, L_{2 A}=L_{A}$. Consequently, equation (A1) implies

$$
w_{B}=\frac{\alpha \mu L_{A}}{(1-\beta) L_{B}} .
$$

Substituting into conditions (A2) and (A3), we find that this regime holds if and only if

$$
a<\frac{\alpha L_{A}}{(1-\beta) L_{B}}<\frac{b}{\mu}
$$

which characterizes regime (P1). Note that this regime may only hold if $b>a \mu$.

\section{P2: Monopoly Pricing, Country A Produces Both Goods}

Let us now look for a regime where country A produces some 1-goods, assuming again monopoly pricing in the 2-goods. This will be the case if (A2) holds and if

$$
w_{B} \geq b .
$$

Given that $p_{1}=w_{B} / b$, if $p_{1}>1$, then it is profitable for producers of 1 -goods in country A to cover the whole market, leaving no output for producers in country B (the standard dominant firm result). That cannot be true in equilibrium, as it contradicts the full employment condition in country B and the assumption that country B only produces 2 -goods. Therefore in such a regime it must be that $w_{B}=b$. Profits are equal to zero for producers of 1-goods in country A. $L_{2 A}$ is then determined by (A1), yielding

$$
L_{2 A}=\frac{(1-\alpha) L_{A}+b(1-\beta) L_{B}}{\alpha \mu+1-\alpha} .
$$

For this regime to hold, it must be that (A2), holds, i.e. $\mu<b / a$, and that $L_{2 A} \leq L_{A}$, that is

$$
\frac{b}{\mu}<\frac{\alpha L_{A}}{(1-\beta) L_{B}}
$$

This therefore characterizes regime P2.

\section{P'1: Limit Pricing, Country A Only Produces 2-Goods}

Now let us consider the possibility of limit pricing in 2-goods, and no production of 1-goods in country A. That corresponds to the following conditions:

$$
p_{2}=\frac{w_{B}}{a}<\mu
$$

and

$$
w_{B}<b .
$$

One then has $L_{1 A}=0, L_{2 A}=L_{A}$ Plugging these conditions into (A1), we find that this is a knife-edge case which can only hold if $\alpha L_{A} / a=(1-\beta) L_{B}$. We shall therefore ignore it. 


\section{P3: Limit Pricing, Country A Produces Both Goods}

Now consider the case of limit pricing in 2-goods, and some production of 1-goods in country A. We again have $p_{2}=\frac{w_{B}}{a}<\mu$ and $w_{B}=b$. Substituting into (A1) we get

$$
L_{2 A}=\frac{(1-\alpha) L_{A}+b(1-\beta) L_{B}}{\alpha b / a+1-\alpha} .
$$

This regime holds if $b / a<\mu$ and $L_{2 A}<L_{A}$, or equivalently

$$
a<\frac{\alpha L_{A}}{(1-\beta) L_{B}} .
$$

Thus we have characterized regime P3.

\section{P4: Country B Produces Both Goods}

Now let us look at an equilibrium where country B produces both goods. It must be that $p_{1}=w_{B} / b$ and $p_{2}=w_{B} / a$. For country B to produce some of the 2-goods, it must be that $p_{2} \leq w_{A}=1$, otherwise monopolists in country A would flood the market.

Assume $p_{2}<1$, then a fortiori $p_{1}<1$, as $b>a$. Then, no producer in country A would be profitable, which contradicts the full employment condition there. Thus we must have $p_{2}=1$, implying $w_{B}=a$. Then $p_{1}=a / b<1$, implying that country A does not produce 1-goods. The equilibrium is then easily characterized. Profits in country A are equal to zero, GDP in country $A$ is

$$
Y_{A}=w_{A} L_{2 A}=L_{A}
$$

and GDP in country B is given by

$$
Y_{B}=w_{B} L_{B}=a L_{B}
$$

Equilibrium in the goods markets can be written

$$
\alpha \frac{Y_{A}}{p_{1}}+\beta \frac{Y_{B}}{p_{1}}=b L_{1 B}
$$

implying

$$
L_{1 B}=\frac{\alpha L_{A}+\beta a L_{B}}{a} .
$$

For this regime to hold we must have $L_{1 B}<L_{B}$, i.e.

$$
\frac{\alpha L_{A}}{(1-\beta) L_{B}}<a \text {. }
$$

This therefore characterizes regime $\mathrm{P} 4$.

\section{Derivation of the 3 Enforcement Regimes}

We now turn to the enforcement regime. In this regime all production units are owned by the monopolist in country 2, regardless of where they are located. Prices are thus always equal to the markup times the wage in the country where the good is being produced. 


\section{E1: Country A Only Produces 2-Goods and Country B Only Produces 1-Goods}

First consider the case where country A only produces 2-goods and country B only produces 1-goods. We then have

$$
\begin{aligned}
& p_{1}=\mu w_{B} / b ; \\
& p_{2}=\mu w_{A}=\mu .
\end{aligned}
$$

GNP for country A's residents is

$$
Y_{A}=p_{2} L_{A}+(\mu-1) w_{B} L_{B}
$$

where the second term represents profits repatriated from country B. GNP in country B is given by

$$
Y_{B}=w_{B} L_{B}
$$

Equilibrium in goods markets is given by

$$
(1-\alpha) \frac{Y_{A}}{p_{2}}+(1-\beta) \frac{Y_{B}}{p_{2}}=L_{A}
$$

Substituting (A5)-(A8) we get

$$
w_{B}=\frac{\alpha \mu L_{A}}{(1-\beta) L_{B}+(1-\alpha)(\mu-1) L_{B}} .
$$

For this regime to be an equilibrium, it must be that firms do not want to relocate in the other country. Consider first a monopoly based in country A. Its profit is given by

$$
\pi_{2}=(\mu-1) c_{2},
$$

where $c_{2}=L_{A} / N_{2}$ is the amount sold of each 2-good.

If it decides to relocate in country $\mathrm{B}$, its unit cost is $w_{B} / a$. It will charge $p_{2}^{\prime}=\mu w_{B} / a$, and sell a quantity equal to $c_{2}^{\prime}=c_{2}\left(p_{2}^{\prime} / p_{2}\right)^{-\sigma}$, so that its profits are

$$
\pi_{2}^{\prime}=c_{2}(\mu-1)\left(w_{B} / a\right)^{1-\sigma} .
$$

We must have $\pi_{2}^{\prime} \leq \pi_{2}$, i.e. $w_{B} / a>1$. Similarly, for producers of 1-goods not to want to relocate in country $\mathrm{A}$, we need $w_{B} / b<1$. These two inequalities are equivalent to

$$
a<\frac{\alpha \mu L_{A}}{[(1-\beta)+(1-\alpha)(\mu-1)] L_{B}}<b,
$$

and this characterizes regime E1. It is then straightforward to compute profits.

\section{E4: Country B Produces Both Goods, Country A Only 2-Goods}

Now consider an equilibrium where country B produces 1-goods and 2-goods, and country A produces only 2-goods. Producers of 2-goods must be indifferent between locating in country A and locating in country $\mathrm{B}$, therefore we must have $w_{B} / a=w_{A}=1$. Hence

$$
w_{B}=a .
$$


Consequently, $p_{2}=\mu$ and $p_{1}=\mu a / b$. Equations (A7) and (A8) still hold, while (A9) must be replaced by

$$
(1-\alpha) \frac{Y_{A}}{p_{2}}+(1-\beta) \frac{Y_{B}}{p_{2}}=L_{A}+a L_{2 B} .
$$

Substituting, this allows to compute $L_{2 B}$ :

$$
L_{2 B}=\frac{(1-\beta) a L_{B}+(1-\alpha)(\mu-1) a L_{B}-\alpha \mu L_{A}}{\mu a} .
$$

For this regime to be an equilibrium, one must have $0<L_{2 B}<L_{B}$, which, as the second inequality $L_{2 B}<L_{B}$ is always satisfied, is equivalent to

$$
\frac{\alpha \mu L_{A}}{[(1-\beta)+(1-\alpha)(\mu-1)] L_{B}}<a .
$$

This characterizes regime E4.

\section{E2: Country A Produces Both Goods, Country B Only 1-Goods}

Finally, consider a regime where country A produces 1-goods and 2-goods, and country B only produces 1-goods. Equality of unit costs across countries for 1-goods implies

$$
w_{B}=b .
$$

Hence, $p_{1}=p_{2}=\mu$; and equilibrium in goods markets can be obtained by substituting $L_{2 A}$ for $L_{A}$ into the RHS of (A9), yielding

$$
L_{2 A}=(1-\alpha) L_{A}+\frac{b L_{B}}{\mu}[(1-\beta)+(1-\alpha)(\mu-1)] .
$$

This regime holds if $L_{2 A}<L_{A}$, or equivalently

$$
\frac{\alpha \mu L_{A}}{[(1-\beta)+(1-\alpha)(\mu-1)] L_{B}}>b .
$$

This therefore characterizes regime E2. 


\section{Appendix B: Figures}

Figure 3: Gains to Country A

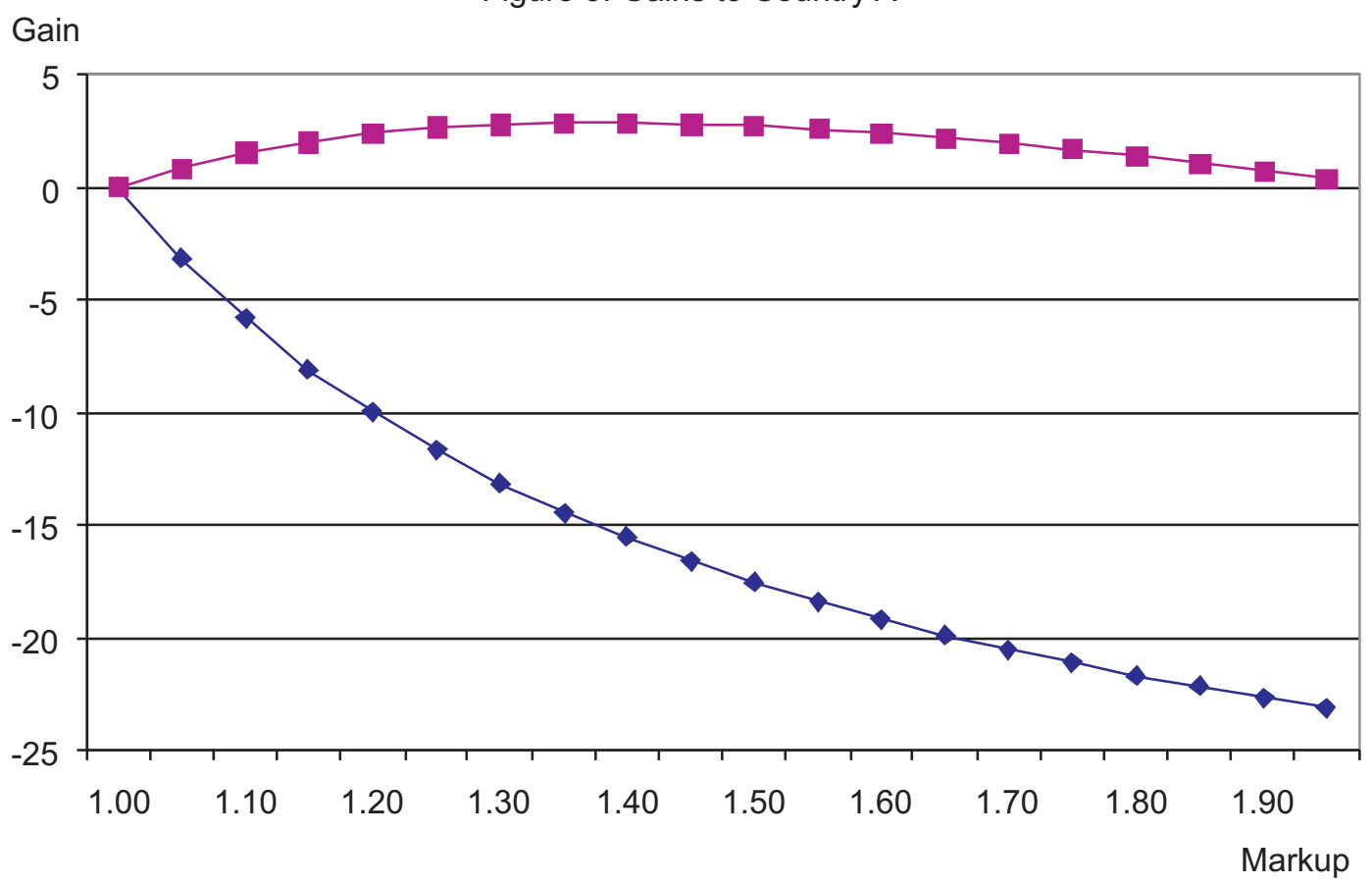

$\checkmark$ Static $\quad-$ Dynamic

Figure 4: Net Gains, Country B

Net gain

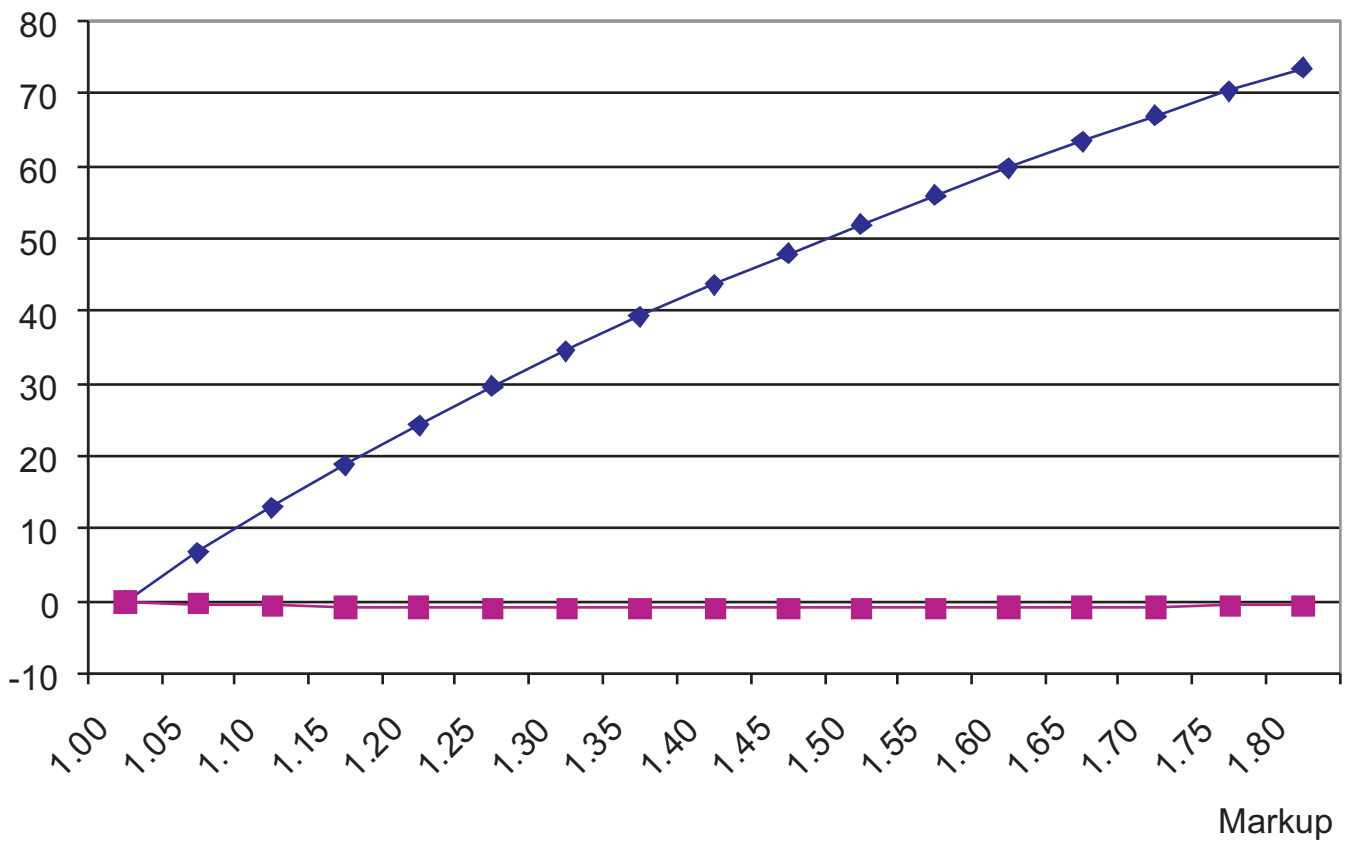

Static - Dynamic 
Critical discount rate

Figure 5: Critical Discount Rate, Country B

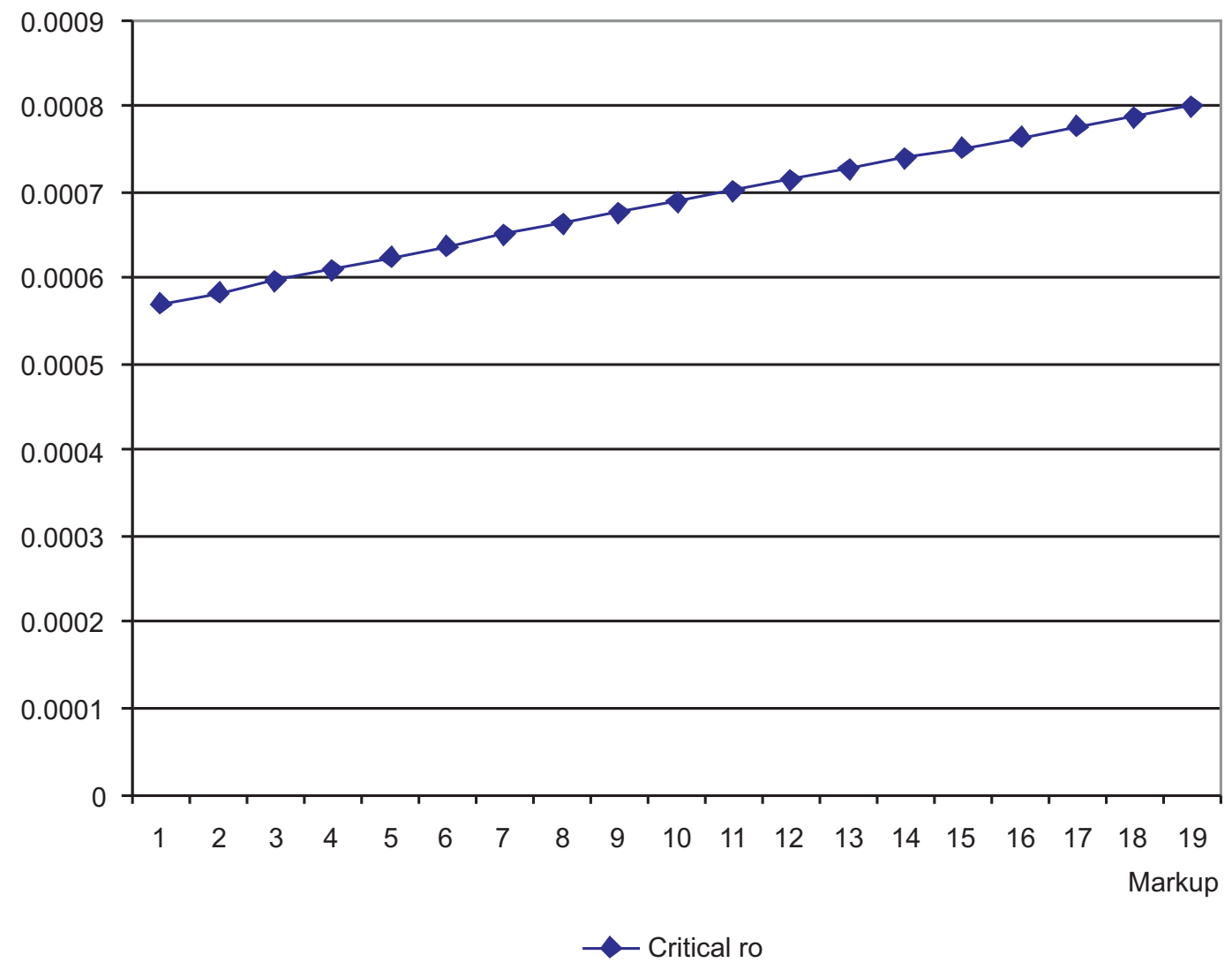

Figure 6: Country A's Gains from Piracy

\section{Gains}

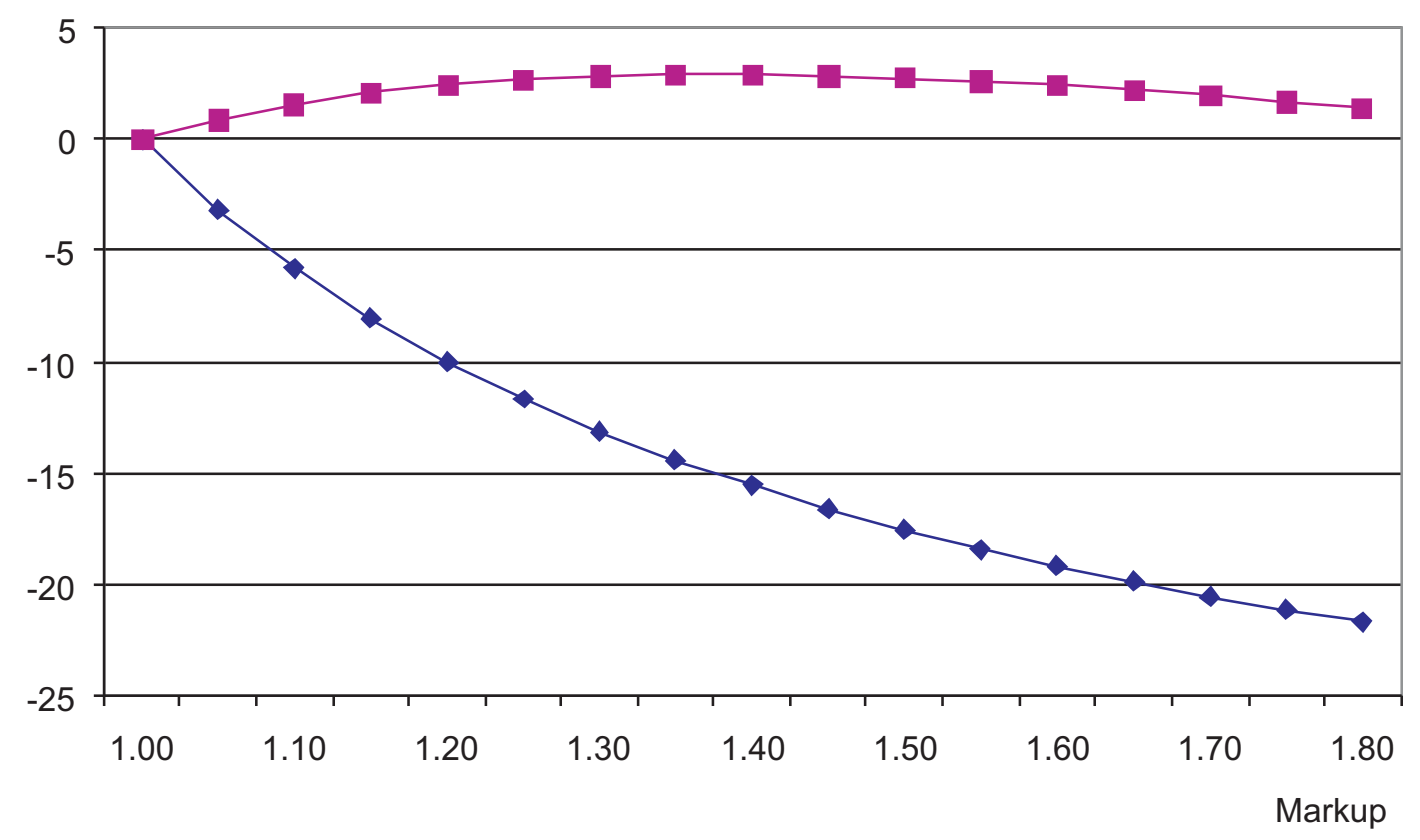

Dynamic 
Critical discout

Figure 7: Critical Discount Rate, Country A

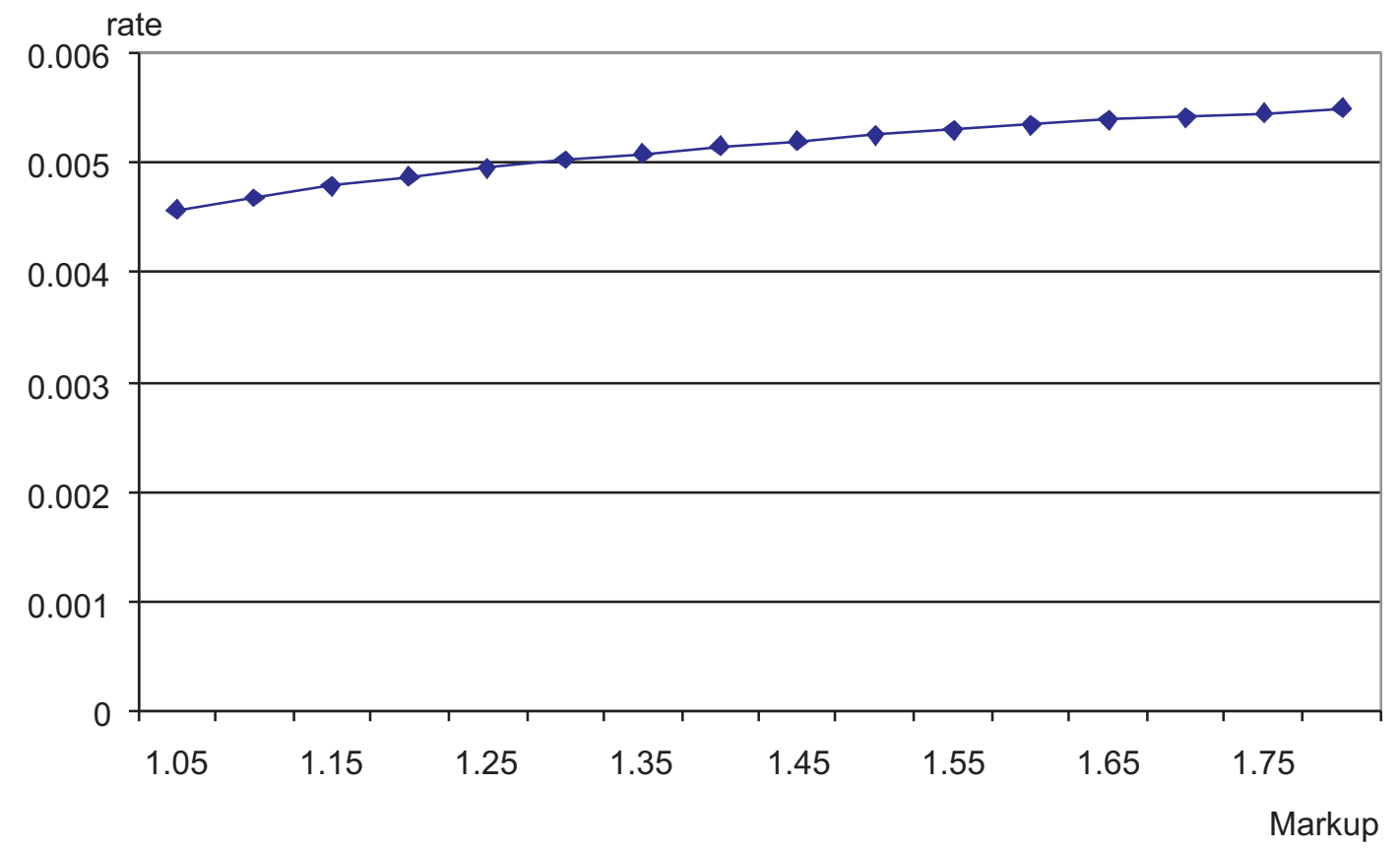

Critical ro

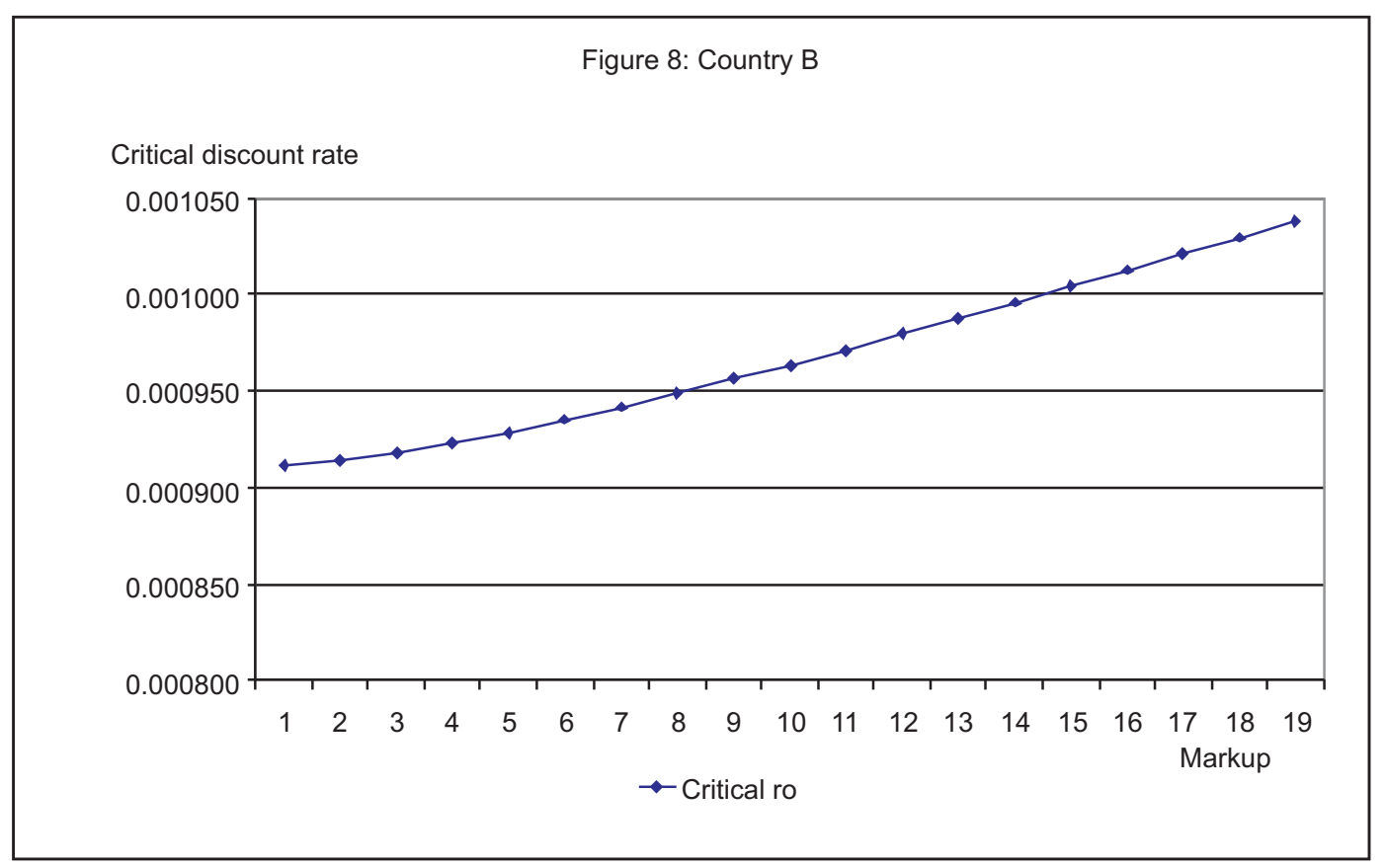


Critical discount rate

Figure 9: Critical Discount Rate, Country B

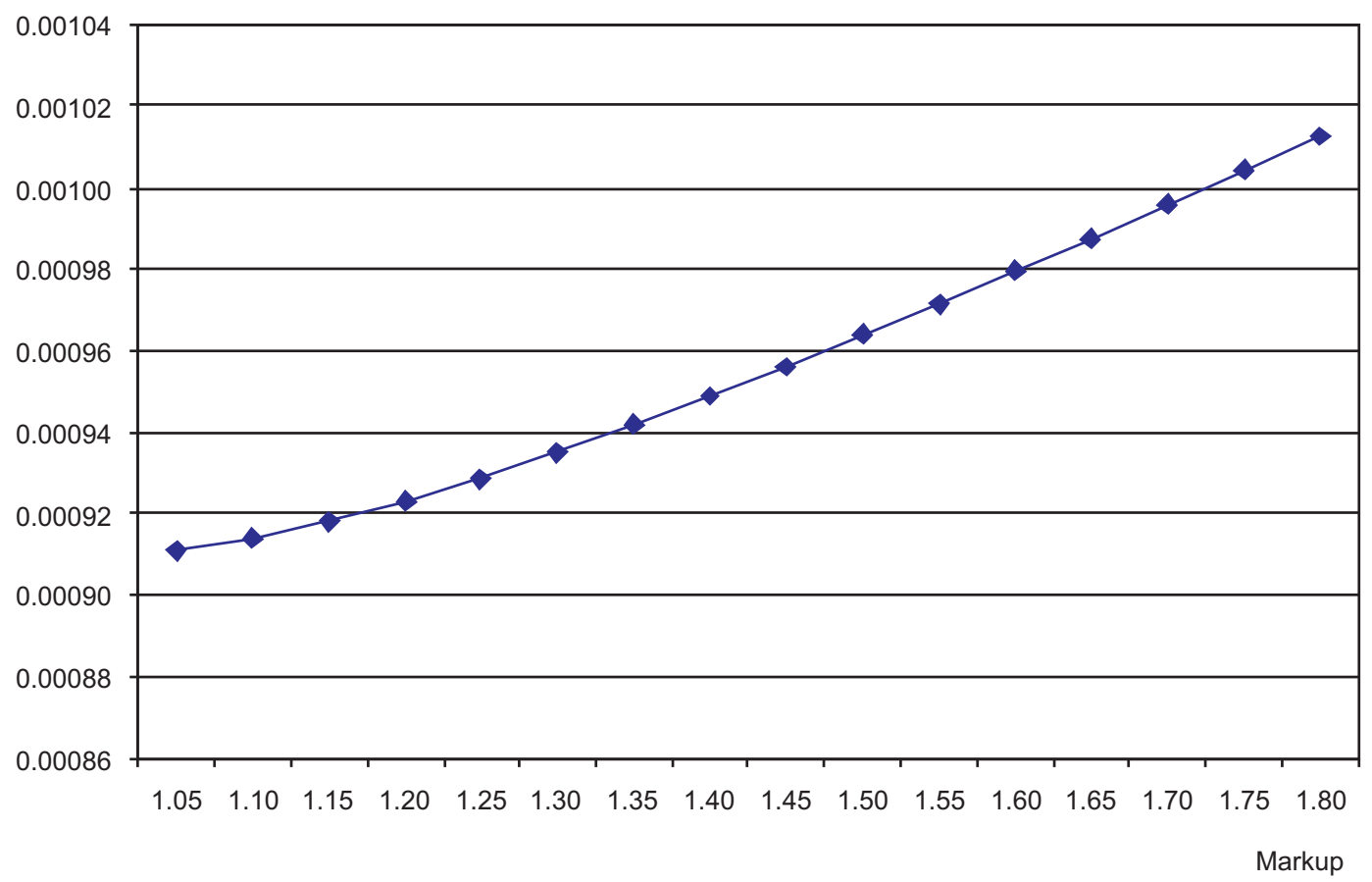

$\neg$ Critical ro 


\section{References}

Benassy, J.-P.l. (1996), Taste for variety and optimum production patterns in monopolistic competition. Economics Letters 52(1): 41-47, 7. http://ideas.repec.org/a/eee/ecolet/v52y1996i1p41-47.html

Diwan, I., and D. Rodrik (1991). Patents, appropriate technology, and North-South trade. Journal of International Economics 30: 27-47. http://ideas.repec.org/a/eee/inecon/v30y1991i1-2p27-47.html

Dornbusch, R., S. Fisher, and P. A. Samuelson (1977). Comparative Advantage, Trade and Payments in a Ricardian Model with a Continuum of Goods. American Economic Review 67: 823-839.

Gancia, G., and A. Bonfiglioli (2007). North-South trade and directed technical change. CREI Working paper, September 2007. http://WwW.crei.cat/people/gancia/pdf_files/NS-DTC.pdf

Goh, A., and J. Olivier (2002). Free Trade and Protection of Intellectual Property Rights: Can We Have One Without the Other? Mimeo, HEC. http://ideas.repec.org/p/cpr/ceprdp/3127.html

Gould, D., and W. Gruben (1996). The role of intellectual property rights in economic growth. Journal of Development Economics 48: 323-350. http://ideas.repec.org/p/fip/feddwp/94-09.html

Grossman, G., and E. Helpman (1991). Innovation and growth in the global economy. MIT Press. $\underline{\text { http;//hooks.google.com }}$

Grossman, G., and E. Lai, (2001). International Protection of Intellectual Property. Discussion papers in economics 215. Princeton University. http://ideas.repec.org/p/fth/priwpu/215.html

Lee, J-Y., and E. Mansfield (1996). Intellectual Property rights protection and US foreign direct investment. Review of Economics and Statistics 78: 181-186. http://ideas.repec.org/a/tpr/restat/v78y1996i2p181-86.html

McCalman, P. (2000). Reaping what you sow: An empirical analysis of international patent harmonization. Mimeo, University of California-Santa Cruz. http://ideas.repec.org/a/eee/inecon/v55y2001i1p161-186.html

Saint-Paul, G. (2005). To what extent should less developed countries enforce Intellectual Property? World Economics 6(3): 175-196.

http://ideas.repec.org/p/cpr/ceprdp/4713.html

Smarzynska, B. (2002). The Composition of Foreign Direct Investment and Protection of Intellectual Property Rights: Evidence from Transition Economies. World Bank Working Paper. http://ideas.repec.org/p/wbk/wbrwps/2786.html 
Smith, P. (1999). Are weak patent rights a barrier to US exports? Journal of International Economics 48: 151-177. http://ideas.repec.org/a/eee/inecon/v48y1999i1p151-177.html

Thoenig, M., and T. Verdier (2003). A Theory of Defensive Skill-Biased Innovation and Globalization. American Economic Review 93( 3): 709-728. http://ideas.repec.org/a/aea/aecrev/v93y2003i3p709-728.html

Yang, G., and K. Maskus (1998). Intellectual Property Rights and Licensing: an Econometric Investigation. Mimeo. http://ideas.repec.org/a/spr/weltar/v137y2001i1p58-79.html 
Please note:

You are most sincerely encouraged to participate in the open assessment of this article. You can do so by either rating the article on a scale from 5 (excellent) to 1 (bad) or by posting your comments.

Please go to:

www.economics-ejournal.org/economics/journalarticles/2008-5

The Editor 